\title{
Effects of Turbulators on an airfoil at low Reynolds number in turbulent flow
}

\author{
Delnero J. S.; Marañon Di Leo J.; Bacchi F.; Colman J.; Scarabino, A. and Boldes U.
}

Laboratorio de Capa Límite y Fluidodinámica Ambiental-Area Departamental Aeronáutica - Facultad de Ingeniería - Universidad Nacional de La Plata - Argentina.

Corresponding author :

Juan Sebastián Delnero,

Laboratorio de Capa Limite y Fluidodinámica Ambiental, Area Departamental Aeronáutica, Facultad de Ingenieria, Universidad Nacional de La Plata, Calle 116 entre 47 y 48, La Plata (1900), Argentina.

Phone/Fax: 00542214236679 - Email: delnero@ing.unlp.edu.ar

\begin{abstract}
The objective of this work is the study of the effect of different configurations of turbulators as flow control devices, when an airfoil is immersed in a flow that reproduces the natural turbulent characteristics of the low atmospheric boundary layer.

The efficiency of an Eppler 387 airfoil modified with several configurations of turbulators is studied. The tests were performed in a boundary layer wind tunnel using an aerodynamic balance and smoke for flow visualizations.
\end{abstract}

Keywords: Turbulence, airfoils, turbulator, low Reynolds number

\section{INTRODUCTION}

It is well known that in aeronautics, turbulators are used in a given fly condition, as passive flow control devices that force the boundary layer to become turbulent. The result of this turbulent condition of the boundary layer is a delay in the flow detachment point (airfoil stall condition) and an increase in the stall angle of attack. [1] For high angles of attack, when the stall condition is reached by the airfoil, the lift force (L) is almost independent of the angle of attach while the drag force (D) increases. It is important in these conditions, to study the changes in the aerodynamic efficiency (L/D).

Turbulators are devices used to generate vortices that energize the boudary layer, delaying its detachment under adverse pressure gradients. They can be fixed to the wing surface, or retractable, to be used in particular situations such as take off, landing and low altitude maneuvers, to delay the stall or to increase the drag as aerodynamic brakes.

A particular turbulator device could produce different effects depending on the incoming flow conditions. It is for that reason that our goal, in the present work, is to establish a relation between effects produced by different turbulators configurations and different flow configurations with the same mean velocity distributions.

When an airplane is manouvering at low altitudes in the low turbulent boundary layer, its behaviour is totally different to the potential flow design conditions.

In the present work we will try to get more information about the behaviour of an Eppler 387 airfoil with different turbulators layouts, submitted to two different turbulent flow configurations. [2]

The turbulent intensity will be from $2 \%$ to $5 \%$, corresponding to the low atmospheric turbulent boundary layer characterisation.

\section{MATERIALS AND METHOD}

This work involved the following stages:
a) Building of airfoil models
b) Characterisation of the wind tunnel turbulence
c) Lift and drag tests
d) Processing and analysis of data 
The tested model is a $0.42 \mathrm{~m}$ chord and $0.80 \mathrm{~m}$ span wing, with a modified Eppler 387 airfoil [3] Two turbulator shapes were tested: romboidal (fig. 1) and wedge-shaped (fig. 2) The test section of the wind tunnel is $7.5 \mathrm{~m}$. long, $1.40 \mathrm{~m}$. wide and $1 \mathrm{~m}$. high [4]

The instantaneous wind velocity data were acquired by means of a Dantec Streamline constant temperature hot wire anemometer, with X-wire film probes, type 55R51. Anemometric data were low-pass filtered at $300 \mathrm{~Hz}$ and sampled at $600 \mathrm{~Hz}$. Then, the instantaneous values were processed in order to obtain the turbulence intensities and the autocorrelation coefficient functions for the different turbulent flows.

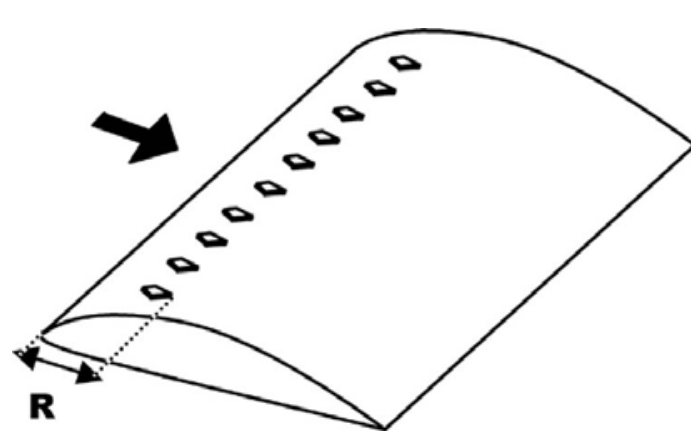

Fig. 1

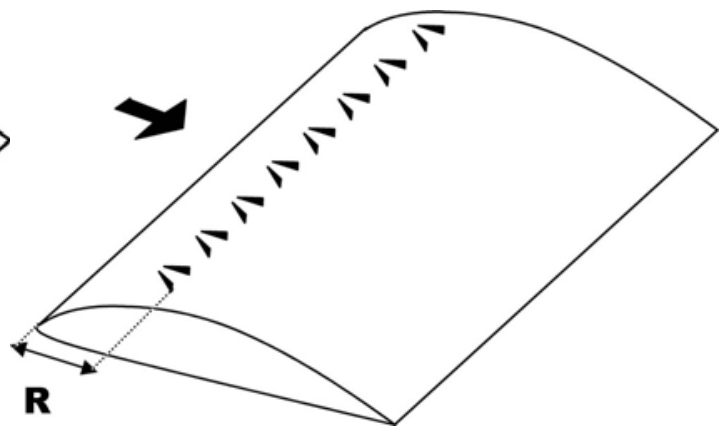

Fig. 2

The upstream reference velocity was measured with a hot wire anemometer-thermometer Dantec Flowmaster. An array of horizontal airfoils of variable incidence at the entrance of the wind tunnel test section and prismatic roughness elements were used in order to obtain the desired turbulent structure of the flow, characteristic of the low atmospheric boundary layer of diverse environments [5], as seen in fig. 3. Through a trial and error procedure several experiments were made until the target mean velocity, turbulence intensity and turbulent scales were reached [6]. Flat plates parallel to the flow were placed next to the wing ends in order to keep the mean flow two-dimensional over the wing [7].

A two-component strain gauge balance fixed to one of the wing main spars was used for the measurements of aerodynamic lift and drag. Its output is fed into a PC by a Vishay 2310 signal conditioning amplifier [8], and sampled at a rate of $500 \mathrm{~Hz}$.. The airfoil lift and drag coefficients, $C_{L}$ and $C_{D}$, are computed respectively from the vertical and longitudinal forces measured by the balance [9]. This coefficients are plotted versus the angle of attack in the airfoil characteristic curves $C_{L^{-}} \alpha$, and in the graphs $C_{L}$ vs. $C_{D}$ and airfoil efficiency, $C_{L} / C_{D}$ vs. $\alpha$ [10] [11].

The geometry and distribution of the tested turbulators are as following:

Turbulators type I are wedges $3 \mathrm{~mm}$ high, $30 \mathrm{~mm}$ long and of thickness $1.5 \mathrm{~mm}$. They were mounted on the wing at angles of $+/-20^{\circ}$ with the direction of the wing chord, with their centers $40 \mathrm{~mm}$ apart (fig. 2).

Turbulators type II are small parallelograms (rhombus), with diagonals $16 \mathrm{~mm}$ and $14 \mathrm{~mm}$ long and thickness $1.5 \mathrm{~mm}$, mounted on one side, with the apex corresponding to the longest diagonal facing the incident flow

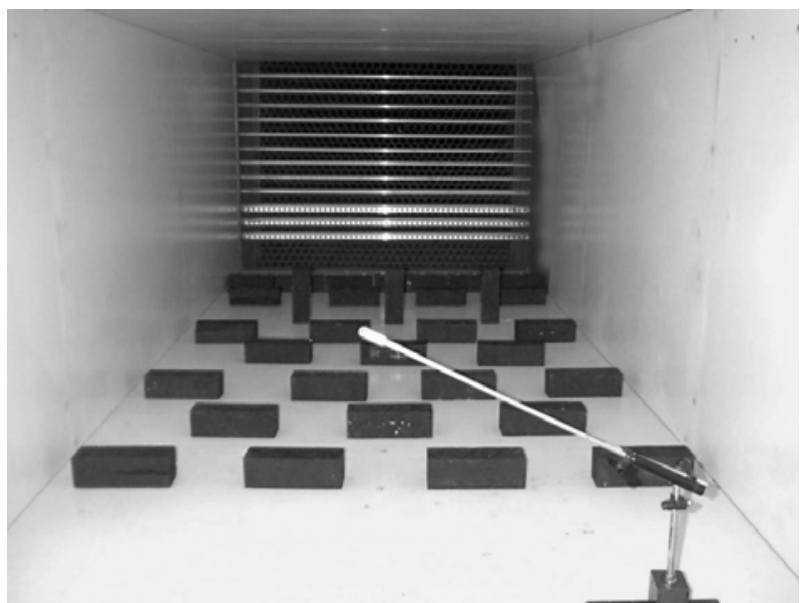

Fig. 3 
Both types of turbulators are mounted at a distance $\mathrm{R}$ of the airfoil leading edge, equal to $15 \%$ of the wing chord.

The temperature and mean velocity were recorded during the test, as well as vertical and longitudinal forces on the wing, for different angles of attack. The lift and drag coefficients were computed from this measurements, considering a correction for temperature. A blockage correction for wind tunnel effects was applied. [12].

The wind mean velocity was $10 \mathrm{~m} / \mathrm{s}$, giving a Reynolds number of 365000 for two different types of turbulence. [13].

\section{RESULTS}

The tests were performed with a mean velocity of $10 \mathrm{~m} / \mathrm{s}$ and turbulence intensities of $2 \%$ (Turbulence I) and 5 $\%$ (Turbulence II) The longitudinal length scales were obtained from the integral time scales, with Taylor's frozen flow hypothesis [14]. The time scales were approximated as the intersection with 0 of the initial slope of the autocorrelation coefficient curve (Fig. 4). This criterium gives the exact value in the case of an exponential decay. The time scale for turbulence II was $0.02 \mathrm{~s}$, giving a length scale of $0.2 \mathrm{~m}$, aprox. one half of the wing chord. The time scale of turbulence I is $0.006 \mathrm{~s}$, giving a length scale of $0.06 \mathrm{~m}, 15 \%$ of the wing chord.

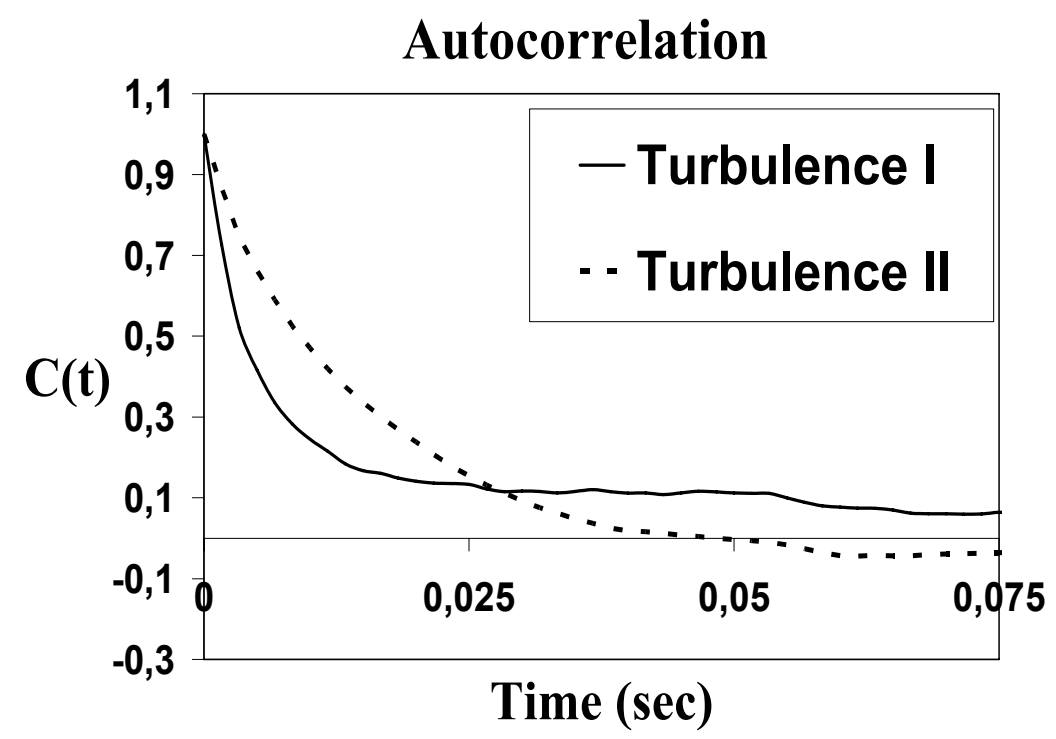

Fig. 4

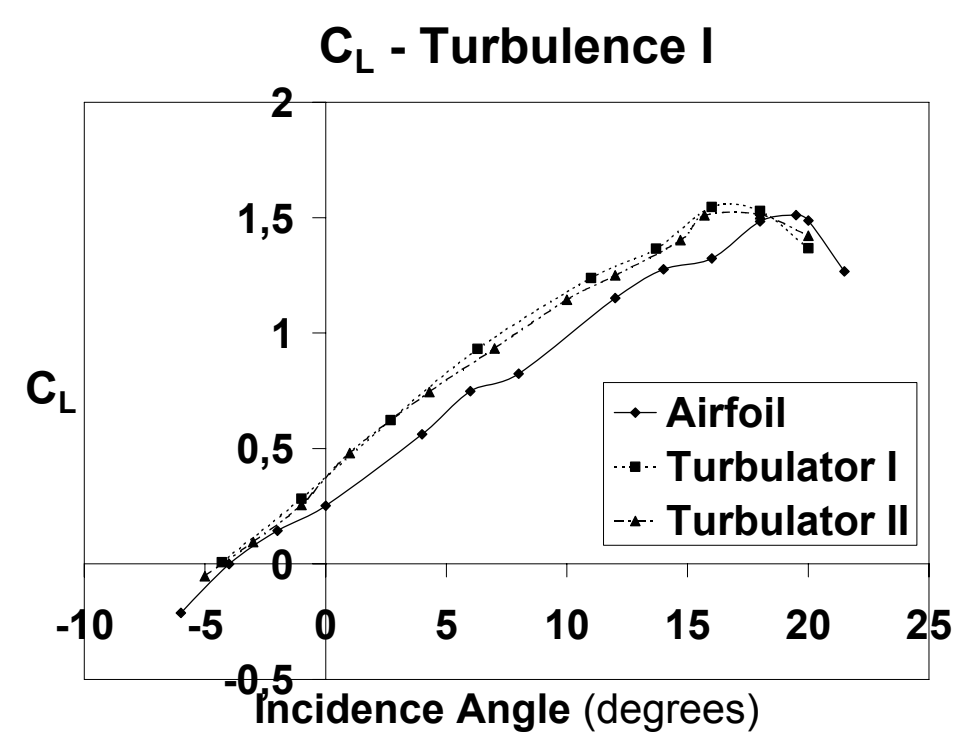

Fig 5 


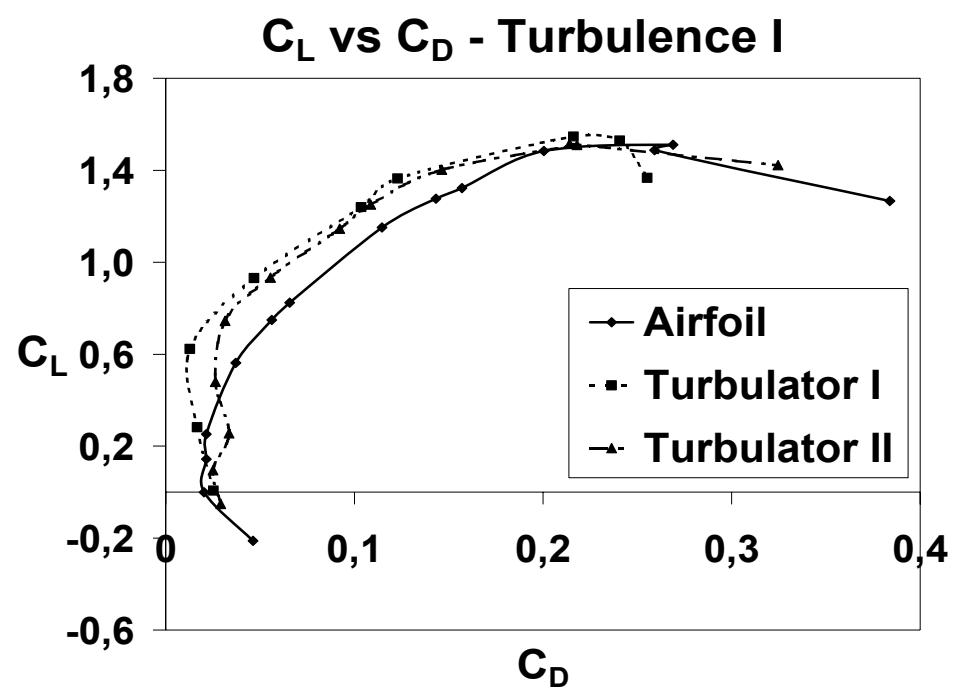

Fig. 6
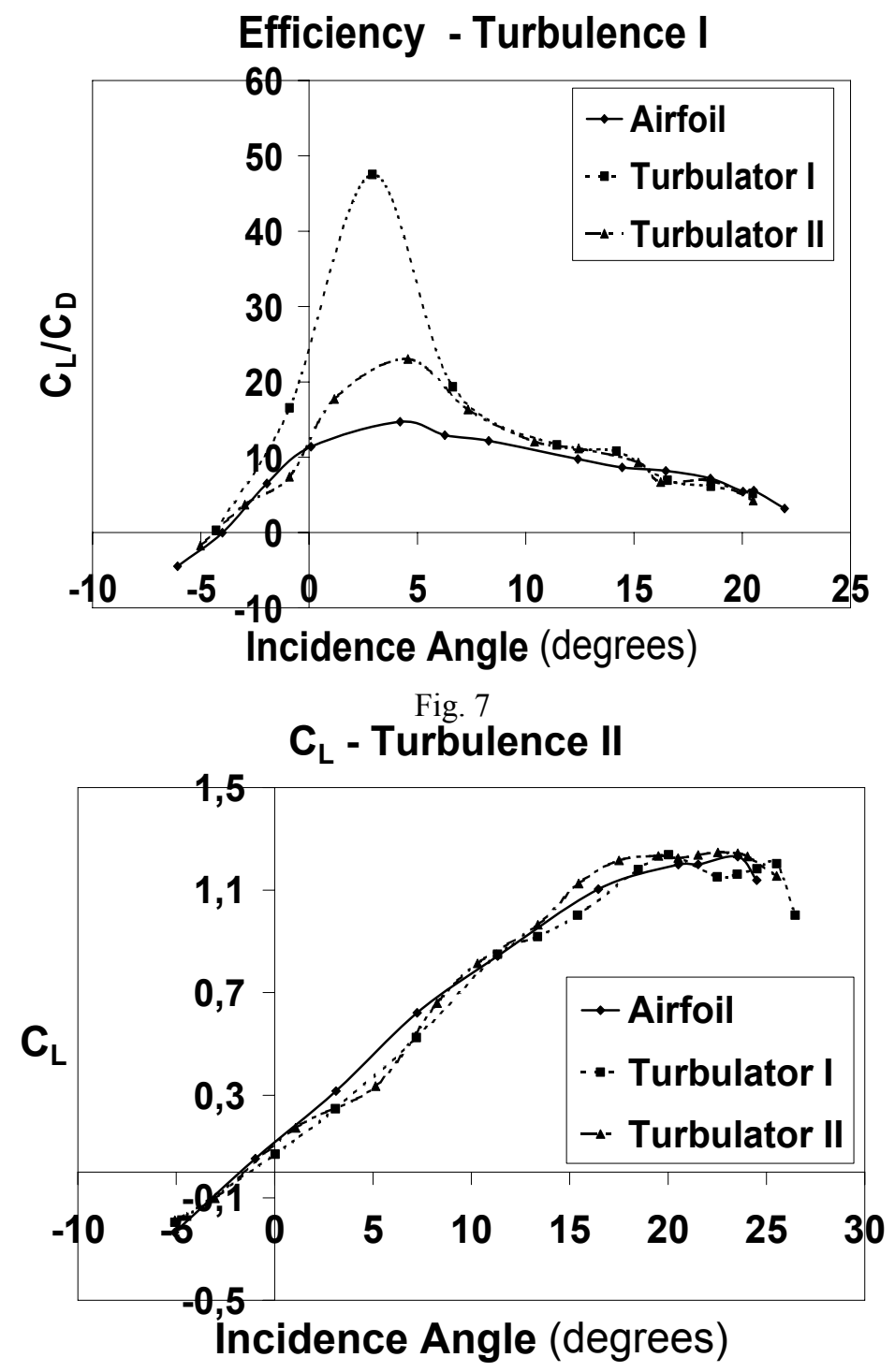

Fig. 8 


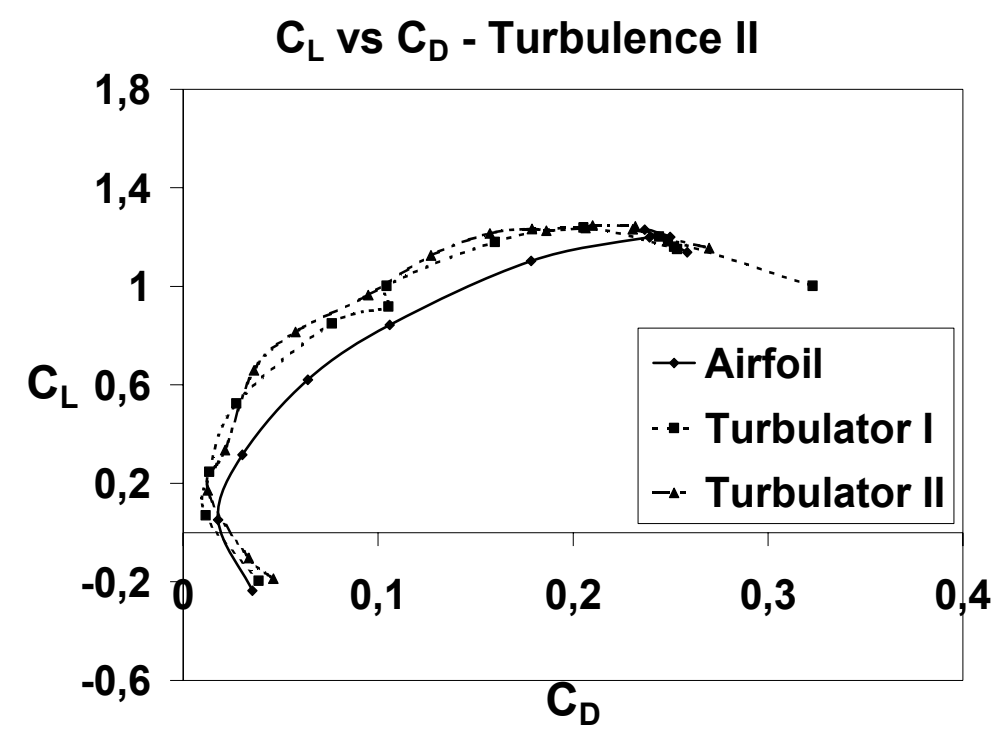

Fig. 9

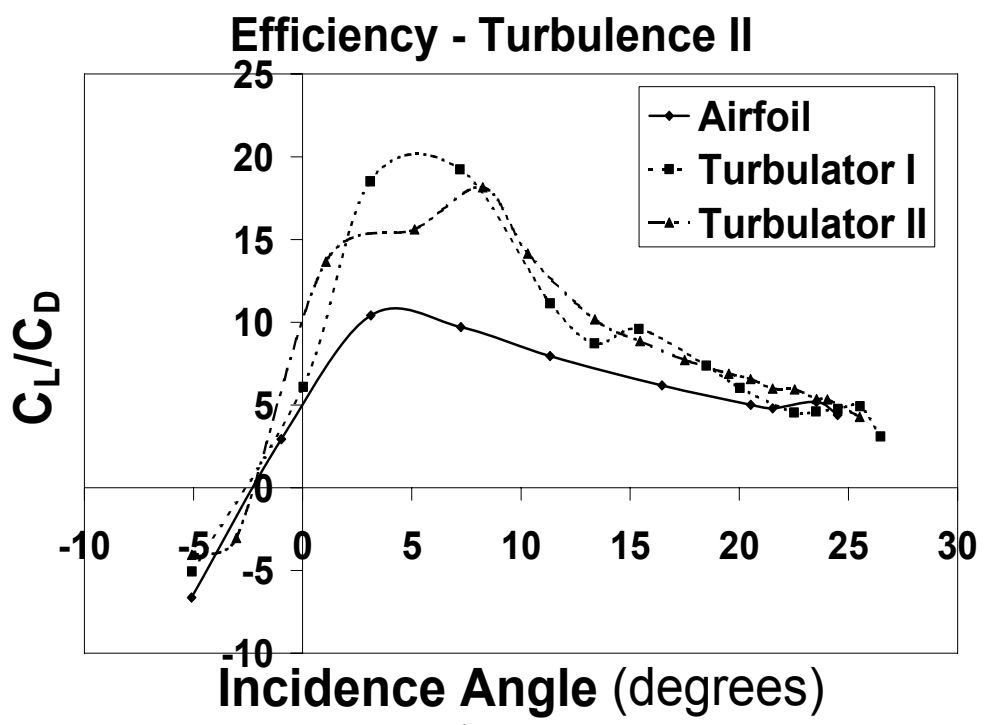

Fig. 10

From the analysis of the curves we can see that, for Turbulence I, the stall angle of attack is higher for the plain wing than for the wing with turbulators. However, for the case with turbulators the curves show less drag and larger efficiency (Figures 5, 6 and 7).

For Turbulence II, no important changes could be observed in the $\mathrm{C}_{\mathrm{L}}$, among the three cases. However, the drag and effciency curves show similar behaviour as in Turbulence I. (Figures 8, 9 and 10).

\section{CONCLUSIONS}

(All data results included in this preliminary version are based in only one test performed, and are subjected to change as following tests might suggest. However we considered important to include them as long as they show the trend of future results).

The normal purpose of turbulators is to generate a turbulent flow on the wing extrados in conditions close to stall, in order to energize the boundary layer to both delay the stall and reattach the flow. In this way higher lift can be achieved and sustained. [15]

On the other hand, when the incident flow is already turbulent, the boundary layer for this range of Reynolds numbers is naturally turbulent, thus the effect of turbulators and their efficiency in the airfoils performance will be different [16]. 
As concluding remarks, in the first observation, we can say that there is some evidence that shows a relation among the performance of the airfoil, the turbulent configuration of the flow field and the different types of turbulators studied.

At the moment the authors are in the evaluation of the data and elaboration of the final conclusions. The full paper will have those results and complete conclusions.

\section{REFERENCES}

[1] Chung, M.Y. "ES30D Fluid Mechanics II. Chap. 11 Flow Control and Wind Design”. School of Engineering \& Centre for Scientific Computing, University of Warwick, Great Britain, 33 pages, 2004.

[2] Liebeck, R.H. "Desing of Airfoils for High Lift". AIAA paper 80-3034, 1980.

McCormick, Barnes, “Aerodynamics, Aeronautics, and Flight Mechanics,” Ed. John Wiley \& Sons, (1995).

[3] Lyon, C.; Broeren, P.; Giguere, A. \& Selig, M. (1995). Summary of Low-Speed Airfoil Data - Volume1, 2 and 3.

[4] Boldes, U., J. Colman and V. Nadal Mora, "The Boundary Layer Wind Tunnel at the Faculty of Engineering, University of La Plata (Argentina)," Latin American Applied Research, 25, 75-85 (1995).

[5] Delnero, J.S.; Marañón Di Leo, J.; Bacchi, F.A.; Colman, J. and U. Boldes. "Experimental determination of the influence of turbulence scale on the lift and drag coefficients of low Reynolds number airfoils". Latin American Applied Research 35, pp 183-188, 2005.

[6] Fuglsang, P.; Dahl, K.S. and Antoniou, I. "Wind Tunnel Test of the Riso A1-18, Riso A1-21 and Riso A1-24 Airfoils”. Riso-1112 (EN), Riso National Laboratory, Roskilde, Denmark, 103pp, 1999.

[7] Liepman, H. W., "Extension of the statistical approach to buffeting and gust response of wings of finite span," Journal of the Aeronautical Sciences, 22, 197-200 (1955).

[8] Wiesnd, A., "Diplomarbeit No 78/1: Experimentelle Bestimmund der LuftKraftbeiwerte von freistehenden Ein - Und Zweifamilienhausern,“ TU München Diplomarbeit $\mathrm{N}^{\circ}$ 78/1 (1978).

[9] Tusche, S. "Interner Bericht: Beschreibung des Konstruktiven Aufbaus und Kalibrierung von 6 Komponenten - DMS - Windkanalwaagen,“ DFVLR Interner Bericht 29112-83 A 11 (1984).

[10] Hoerner S.F., "Fluid - Dynamics Lift," Published by the Author (1975).

[11] Bertin, J. J.; M. L. Smith M.L. “Aerodynamics For Engineers,” Prentice Hall (1998).

[12] Barlow, J. B., W. H. Rae and A. Pope, "Low-Speed Wind Tunnel Testing," John Wiley \& Sons, 3rd edition, 353-361 (1999).

[13] Hinze J. O., “Turbulence,“ Ed. Mc Graw-Hill (1975).

[14] Bruun, H. H., "Hot Wire Anemometry. Principles and signal analysis," Oxford university Press Inc., New York (1995).

[15] Green, R.B. and Galbraith, R.A. "Comment on dynamic airfoil flow separation and reattachment". Journal of Aircraft 33, pp 1211-1216, 1996.

[16] McKeough, P. J. and J.M.R. Graham, "The effect of mean loading on the fluctuating loads induced on aerofoils by a turbulent stream," The Aeronautical Quarterly, 31, 56-69 (1980). 